\title{
Ekonomik Büyüme ve Gelir Eşitsizliği İlişkisi: Kuznets Ters-U Hipotezi'nin Geçerliliği ${ }^{1}$
}

Seher Gülşah TOPUZ

Arş. Gör., Eskişehir Osmangazi Üniversitesi iiBF, iktisat Bölümü stopuz@ogu.edu.tr

Özcan DAĞDEMIR

Prof. Dr., Eskişehir Osmangazi Üniversitesi iiBF, iktisat Bölümü dagdemir@ogu.edu.tr

Ekonomik Büyüme ve Gelir Eşitsizliği iliş̧kisi: Kuznets Ters-U Hipotezi'nin Geçerliliği

\section{Özet}

$\mathrm{Bu}$ çalışma ülkeleri gelişme seviyelerine göre sınıflandırarak ekonomik büyümenin gelir eşitsizliği üzerindeki etkilerini tespit etmeyi amaçlamaktadır. Düşük ve düşük-orta gelirli ülkeler, üst-orta gelirli ülkeler, yüksek gelirli ülkeler ve tüm ülkeler olmak üzere dört farklı panelde Kuznets'in ters-U hipotezinin geçerliliği sınanmaktadır. Çalışmada ekonomik büyüme ve gelir eşitsizliği ilişkisi 1995-2011 yılları arası verileri kullanılarak 94 ülke için incelenmektedir. Çalışmanın bulguları Kuznets hipotezini desteklemektedir. Düşük ve düşük-orta gelirli ülkeler ile üst-orta gelirli ülkelerde ekonomik büyüme ile gelir eşitsizliği artarken; yüksek gelirli ülkelerde ekonomik büyüme ile gelir eşitsizliği azalmaktadır. Çalışmanın sonuçları, ekonomik büyümenin gelir eşitsizliğini azaltmaya yönelik politikalarla desteklenmesi gerektiğini göstermektedir.

Anahtar Kelimeler: Ekonomik Büyüme, Gelir Eşitsizliği, Kuznets Eğrisi
The Relationship Between Economic Growth and Income Inequality: The Validity of Kuznets inverted-U Hypothesis

\section{Abstract}

This study aims to determine effects of economic growth on income inequality by classifiying countries in terms of their level of development. The validity of Kuznets's inverted-U shaped hypothesis is tested for four different panels that is divided as low and low-middle income countries, upper-middle income countries, high income countries and all countries. This paper examines that the relationship between economic growth and income inequality by using data for the period of 1995-2011 and 94 countries. The evidences support Kuznets's hypothesis. Income inequality decreases with economic growth in high income countries, while it increases in low and low-middle income and upper-middle income countries. The results indicate that economic growth should be supported by the policies reducing income inequality.

Keywords: Economic Growth, Income Inequality, Kuznets Curve

1 Bu çalışma Prof. Dr. Özcan DAĞDEMiR'in danışmanlığında Eskişehir Osmangazi Üniversitesi, Sosyal Bilimler Enstitüsü’nde yürütülen, Seher Gülşah Topuz'un "Finansal Gelişme Sürecinde Gelir Eşitsizliği: Bir Panel Veri Analizi” (2013) başııkı Yüksek Lisans Tezi'nden yararlanılarak hazırlanmıştır. 


\section{Giriş}

Ekonomik gelişme ve gelir eşitsizliği ilişkisi ekonomistler arasında uzun yıllardır devam eden bir tartışma konusudur. Iliş̧kinin araştırılması 1955 yılında Simon Kuznets'in ileri sürdüğü hipotezle önem kazanmaya başlamıştır. Kuznets'e göre ekonomik gelişmenin başlangıç aşamalarında ekonomik büyüme ile birlikte gelir eşitsizliği artarken, ekonomik gelişmenin ileri aşamalarında ekonomik büyüme ile gelir eşitsizliği azalmaktadır. Ekonomik gelişmenin iki farklı aşamasında zamanla gelir eşitsizliğinin çizdiği bu yol ters-U şeklinde bir seyir izlemektedir. Kuznets'in sadece Almanya, İngiltere ve ABD'nin veri setiyle yaptığı zaman serisi çalışmasında elde ettiği bu hipotez birçok çalışmaya da yol gösterici nitelikte olmuştur.

Elde edilen sonuçlar oldukça tartışmalı olmasına rağmen Kuznets ile başlayan teorik görüşleri ise sonraki yıllarda yapılan ampirik çalışmalar izlemektedir. Kuznets hipotezini değerlendirmek için gerekli olan gelir dağılımı veri seti 1970'lerin ortasına kadar oldukça sınırlı olduğundan zaman serisi analizinden ziyade çalışmalarda kesitveri analizinden yararlanılmıştır. Yapılan ampirik çalışmaların tartışmalı sonuçlarında dört temel durum olduğu ortaya çıkmaktadır: negatif ilişkiyi doğrulayan çalışmalar; pozitif kanıtlar bulanlar; doğrusal olmayan bir ilişkinin varlığını ileri sürenler ve son olarak da bu iki değişken arasında ilişki olmadığını kanıtlayan çalışmalardır.

Ekonomik büyüme ve gelir eşitsizliği ilişkisi ekonomistler ve politika yapıcılar tarafından uzun zamandır araştııımaktadır. Bu çalışmayı literatürdeki diğer çalışmalardan ayıran özellik analize dahil edilen 94 ülkenin Dünya Bankası'nın gelir ayrımına göre sınıflandırılarak incelenmesidir. Bu ayrıma göre düşük ve düşük-orta gelirli, üst-orta gelirli ve yüksek gelirli olmak üzere üç grup oluşturulmaktadır. Her bir grup örneklemi için ilişki üç farklı panelde ayrı ayrı incelenmiş, son olarak da tüm ülkelerin dahil olduğu bir örneklemle hipotez sınaması yapılmıştır. Temel amaç ekonomik gelişmişlik düzeyinin artması halinde her bir ülke grubunda gelir eşitsizliğinin durumunun ne olacağını tespit etmektir. Bu amaçla literatürde ortaya çıkan temel hipotez olan Kuznets'in ters-U hipotezi test edilmektedir.

\section{Literatür Taraması}

Literatürde ekonomik gelişme ve gelir eşitsizliği ilişkisini Kuznets'in çalışmasını temel alarak inceleyen birçok çalışma var olmasına rağmen, çalışmaların sonuçları incelendiğinde bir fikir birliğine varılamadığı görülmektedir. Bunun nedenleri için ise kullanılan yöntem, veri seti ve dönemsel farklar olduğu söylenebilir.

Paukert (1973), 56 ülke için gelir eşitsizliğinin ekonomik gelişme üzerindeki etkisini incelemiştir ve gelişmiş ülkelerde gelir eşitliğinin gelişmekte olan ülkelerden daha yüksek olduğu sonucuna varmıştır. Bu ise Kuznets hipotezini destekleyen sonuçlar elde ettiğini göstermektedir. Ahluwalia (1976), gelişmenin farklı seviyelerindeki 60 ülke için bağımlı değişken olarak farklı yüzdelik dilim gelir dağılım oranlarını 
kullanarak ülkeler arasındaki eşitsizlik ve gelir ilişkisini test etmiştir. Kuznets'i destekleyici kanıtlar elde etmiştir ancak her ülke için bir gözleme sahip olması ve ülkeler arasında ölçüm farkları olması araştırmayı sınırlandırmaktadır. Thornton (2001), 96 ülke verisi ile yaptığı panel veri analizinde bağımlı değişken için Gini katsayısını kullanarak ters-U eğrisinin dönüm noktasını hesaplamıştır. Analizinde Deininger ve Squire (1996)'in veri setini kullanan Thornton'un elde ettiği sonuçlar kişi başına düşen reel GSYiH ile eşitsizlik arasında Kuznets hipotezini destekleyen kanıtlar sunmaktadır. Ram (1989) ise Kuznets hipotezini test etmek amacıyla 115 piyasa ekonomisi için 1960-1980 döneminin geniş örneklemini kullanmıştır. Ülkeler arasındaki farklılıkları kontrol etmek üzere Theil indeksinden yararlanmıştır. Elde edilen sonuçlar burada da ters-U hipotezini doğrulamaktadır. Ram daha sonra 1997 yılında yaptığı çalışmasında ise 19 gelişmiş ülke için değişkenler arasında U şeklinde bir ilişki olduğunu elde etmiştir. Dawson (1997), 36 az gelişmiş ülke örneği ile kesit veri analizi yapmıştır. Kuznets'in orijinal fonksiyonu ve yarı logaritmik fonksiyon kullanarak ilişki analiz edilmiştir ve her ikisinde de Kuznets hipotezi desteklenmiştir. Huang (2004), esnek doğrusal olmayan çıkarım yaklaşımıyla 75 ülke verisini kullanarak Kuznets hipotezinin geçerli olduğuna dair güçlü kanıtlar elde etmektedir. Benzer şekilde Barro (2008), 1960-2000 dönemi ülke verileriyle yaptığı araştırmasında Kuznets'in ters-U hipotezini destekleyen sonuçlar elde etmiştir. Ongan (2004), gelir eşitsizliği, doğrudan yabancı sermaye yatırımları ve Kuznets'in ters-U ilişkisini incelemiştir. Çalışmasında elde ettiği sonuçlar gelir dağılımı ile kişi başına düşen mili gelir arasındaki ters-U ilişkisini desteklemektedir.

Bu çalışmaların yanı sıra Kuznets'in ters-U hipotezini reddeden araştırmacılar da mevcuttur. Shahbaz (2010)'ın amacı gelir eşitsizliği ve ekonomik büyüme arasındaki ilişkiyi hem doğrusal hem de doğrusal olmayan teknik özelliklerle araştırmaktır. Pakistan'ın 1971-2005 dönemindeki yıllık zaman serisi verilerini kullanmıştır. Ampirik kanıtlar Kuznets'in ters-U hipotezini desteklerken; Pakistan için ilişkinin ters-S eğrisi şeklinde olduğunu göstermektedir. Barro (2000), Deininger ve Squire'in geliştirilmiş veri setini kullanarak 1960-1990 dönemi için yaptığı panel analizinde yoksul ülkelerde gelirdeki eşitsizlik ve ekonomik büyüme arasındaki ilişki negatifken zengin ülkelerde pozitif ilişki olduğunu ileri sürmektedir. Bengoa-Calvo ve Sánchez-Robles Rute (2004), 1975-1995 dönemi 16 Latin Amerika ülke örneklemi ile ekonomik büyüme ve gelir eşitsizliği arasındaki teorik ve ampirik ilişkiyi test ederek iki değişken arasında doğrusal olmayan bir ilişki olduğunu elde etmişlerdir. Malinen (2012) de Latin Amerika ülkeleri için ekonomik büyüme ve gelir dağıımı arasındaki uzun dönemli ilişkiyi tekrar tahmin etmiştir. Malinen (2012), gelir eşitsizliği ile büyüme arasında uzun dönemli bir denge ilişkisinin var olduğunu ve bu ilişkinin gelişmiş ülkelerde negatif olduğunu ileri sürmektedir. Chen (2003), 43 ülke ile yaptığı panel veri analizinde değişkenler arasındaki ilişkinin ters-U formunda olduğu sonucuna varmıştır. Ancak Latin Amerika, Asya ve Afrika' da gelir dağılımı ve ekonomik büyüme arasında ilişki olmadığını ileri sürmektedir. Shin (2012)'in genel denge analizi 
metoduyla yaptığı çalışmanın sonuçlarına göre, ekonomik gelişmenin ilk aşamasında gelir eşitsizliği büyümeyi negatif etkilerken; ekonominin durağan durumunda pozitif olarak etkilemektedir. Khasru ve Jalil (2004) de 1963-1999 dönemi için Türkiye'nin de dahil olduğu 24 gelişmiş ve gelişmekte olan ülke verisi ile Kuznets hipotezini yeniden değerlendirmiştir. Hem zaman serisi hem de panel veri analizi kullandıkları çalışmalarında gelir eşitsizliği ve ekonomik büyüme arasındaki ilişkinin tüm ülkelerde aynı olmadığı sonucuna varmışlardır. Özellikle gelişmekte olan ülkelerde ters-U hipotezi geçerli iken gelişmiş az sayıda ülkede $U$ şeklinde ilişki olduğunu elde etmişlerdir. Tokatlıoğlu ve Atan (2007) ise gelişmişlik düzeyi ve gelir eşitsizliği arasındaki ilişkiyi Türkiye için bölgeler düzeyinde incelemiştir. Türkiye'de bölge bazında gelir dağılımı eşitsizliği verilerindeki kısıtlar nedeni ile yatay kesit analizi yaptıkları çalışmalarında Kuznets eğrisinin $U$ şeklinde olduğuna dair kanıtlar bulmuşlardır. Dağdemir (2008) çalışmasında gelişmekte olan ülkeler için 2000'li yıllardaki küreselleşmenin gelir dağılımı üzerindeki etkisini incelemiş̧ir. Analiz sonuçlarına göre gelişmekte olan ülkelerde kişi başına gelir düzeyi arttıkça; yani gelişmenin ileri aşamalarında ters-U hipotezinin doğrulanmadığı görülmektedir.

Son yıllarda ise çok tartışılan ve Kuznets'in ileri sürdüğü hipotezin bazı noktalarını eleştiren bir diğer çalışma, Piketty'nin 21. Yüzyılda Sermaye adlı eseridir. Bu çalışmayı diğer çalışmalardan ayıran nokta ise; yazarın eşitsizlik üzerine yapılan tartışmaları tarihsel temellere dayandırarak sunmasıdır. Piketty, Kuznets Eğrisi teorisini daha çok Soğuk Savaş döneminin ortaya çıkardığı bir durum olarak tanımlamaktadır. 19141945 yılları arasında neredeyse tüm zengin ülkelerdeki eşitsizliğin azalmasının; Kuznets'in ileri sürdüğü gibi toplumsal kesimler arası hareketliliğin değil, dünya savaşlarının ortaya çıkardığı etkilerin sonuçları olduğunu ileri sürmektedir. Piketty, Kuznets'in o dönem için topladığı verilerin sınırlı olduğunu; gelir eşitsizliğinin yapısının analiz edilebilmesi için vergi kayıtlarını toplanması gerektiğini vurgulamaktadır (Piketty, 2014, 16-21).

\section{Teorik Çerçeve}

Kuznets (1955), Amerika, Ingiltere ve Almanya'da iki eyaletin gelir dağılımı değişim verisini kullanarak ekonomik büyüme sürecinde gelir eşitsizliğinin nasıl hareket edeceğini araştırmıştır. Illk olarak Birinci Dünya Savaşından sonra Amerika ve Ingiltere'de gelir eşitsizliğinde keskin bir düşüş olduğunu ve aynı zamanda iki ülkede de önemli gelir büyümesi olduğunu belirlemiştir. Daha sonra Amerika ve İngiltere ile ilgili olan gözlemlerini, ekonomik gelişme sürecinde tarımdan sanayiye tarihsel geçiş ile birlikte birleştirmiş ve gelir dağılımındaki değişimin hangi yönde olduğunu incelemiştir. Elde edilen sonuçlara göre; gelir eşitsizliği, ekonomik büyüme göstergesi olarak alınan kişi başına düşen GSYiH oranı karşısında ters-U şeklinde bir seyir izlemektedir. Kuznets gelişmenin başlangıç aşamalarında eşitsizliğin arttığını, belirli bir eşik değerden sonra ise giderek azaldığını ileri sürmektedir. Kuznets' e göre tarım sektöründeki bireylerin gelirleri sanayi gelirlerinden daha düşüktür; fakat daha eşit 
dağılım göstermektedir. Bu durum göstermektedir ki sanayi sektörüne geçiş bireylerin gelirini artırırken gelir eşitsizliğini de artırmaktadır.

Eşitsizliğin ekonomik gelişmenin başlangıç aşamasında artmasına ilişkin saptaması aslında kullandığı veriden ziyade iki sektörlü bir ekonomi üzerinde varsayılan basit matematiksel uygulamalar sayesinde anlaşılmaktadır. Kuznets (1955) çalışmasında sonuçlarını önemli derece de etkileyecek varsayımlar yapmaktadır: 1) Kişi başına gelir sanayi sektöründe her zaman daha yüksektir; 2) Tarım sektöründeki nüfus zamanla azalmaktadır; 3)Tarım sektöründeki eşitsizlik fazla fakat sanayi sektöründen daha fazla değildir. Bu varsayımlar altında oluşturduğu hipoteze göre, nüfus büyük ölçüde tarım sektöründen sanayi sektörüne doğru kayarken eşitsizlik artmaktadır.

Bu hipotezin altında yatan en önemli varsayımlardan biri tarım ve sanayi sektörü arasındaki gelir farklılıklarıdır; çünkü bu durum beşeri sermayenin bir sektörden diğer bir sektöre göç etmesini teşvik eder. Fakat göç ve şehirleşme eşzamanlı olarak gerçekleşirse, eşitsizlik azalırken ekonomik refah büyümeye devam eder (Brussola, 2011, 15).

Kuznets daha sonra 1963 yılında yaptığı çalışmasında gelişmiş ve gelişmekte olan ülkelerin sınırlı sayıda verisini kullanarak ters-U hipotezini destekleyen daha fazla kanıt elde etmiştir (Kuznets, 1963, 68):

- Gelişmemiş ülkelerde eşitsizlik gelişmiş ülkelere göre daha büyüktür. Göreceli gelir eşitsizliğindeki bu fark, vergilerden önceki gelire göre vergilerden sonraki gelir için daha fazladır.

- Genel olarak gelişmemiş ülkelerde tarım sektöründeki gelir dağılımı sanayi sektöründekine göre daha az eşitsizlik gösterir.

- Gelişmiş ülkelerin gelir dağılımındaki eşitsizlik zamanla daralır; yüksek gelir grubu oranı azalırken düşük gelir grup oranı artar ve iki grup birbirine yaklaşır.

\section{Veri Seti ve Yöntem}

1995-2011 dönemi için verilerine ulaşılabilen 94 gelişmiş ve gelişmekte olan ülke için yapılan analizde gelir eşitsizliği göstergesi olarak kullanılan yıllık Gini Katsayısı verileri United Nations University tarafından hazırlanan World Income Inequality Database'den elde edilmiştir. Diğer tüm değişkenlerin yıllık verileri için ise World Bank Database'den yararlanılmıştır. Ülkeler ve dönemler verilerin ulaşılabilirliğine göre seçilirken gelir seviyesi grupları Dünya Bankası'nın sınıflandırmasına göre yapılmıştır. Ülkeler düşük ve düşük-orta gelirli, üst-orta gelirli ve yüksek gelirli olmak üzere üç gruba ayrılmıştır. Her bir grup için tahmin sonuçları ayrı ayrı değerlendirilmiştir. Son olarak ise tüm gelir gruplarının dahil edildiği panel sonuçları incelenmiştir. Tablo 1'de tüm ülke grupları ve bu gruplara dahil olan ülkelerin hangileri olduğu gösterilmektedir. 
Ekonomik gelişmenin gelir dağılımı üzerindeki etkilerini tahmin edebilmek için dengesiz panel veri analizi ile Sistem-GMM olarak adlandırılan Sistem Genelleştirilmiş Momentler Metodu kullanılmıştır. Arellano-Bover (1995)'ın tanıttığı ve daha sonra Blundell-Bond (1998)'un geliştirdiği Sistem Genelleştirilmiş Momentler Metodu (Sistem-GMM) tekniğinin temeli aslında Arellano- Bond (1991)'un Fark Genelleştirilmiş Momentler Metodu (difference GMM) yöntemine dayanmaktadır. Sonlu örneklem gibi bazı durumlarda Fark Genelleştirilmiş Momentler Metodu zayıf tahmin gücüne sahiptir. Metodun tahmincileri kesinlik noktasında sapmalı olabilmektedir.

Tablo 1: Dünya Bankası Gelir Sınıflandırmasına Göre Ülkeler

\begin{tabular}{|c|c|}
\hline $\begin{array}{l}\text { Düşük ve Düşük-Orta } \\
\text { Gelirli Ülkeler }\end{array}$ & $\begin{array}{l}\text { Ermenistan, Burkina Faso, Bangladeş, Bolivya, Mısır, Etiyopya, } \\
\text { Gürcistan, Guatemala, Honduras, Endonezya, Hindistan, Kırgızistan, } \\
\text { Kamboçya, Fas, Moldova, Madagaskar, Mozambik, Moritanya, Malawi, } \\
\text { Nikaragua, Pakistan, Filipinler, Paraguay, El Salvador, Tacikistan, } \\
\text { Türkmenistan, Uganda, Ukrayna, Özbekistan, Vietnam, Zambiya }\end{array}$ \\
\hline Üst-Orta Gelirli Ülkeler & $\begin{array}{l}\text { Arnavutluk, Arjantin, Azerbaycan, Bulgaristan, Belarus, Brezilya, Şili, } \\
\text { Çin, Kolombiya, Kostarika, Dominik Cumhuriyeti, Ekvator, Iran, Jamaika, } \\
\text { Ürdün, Kazakistan, Litvanya, Letonya, Meksika, Makedonya, Karadağ, } \\
\text { Malezya, Panama, Peru, Romanya, Rusya, Sırbistan, Tayland, Türkiye, } \\
\text { Uruguay, Venezuela, Güney Afrika }\end{array}$ \\
\hline Yüksek Gelirli Ülkeler & $\begin{array}{c}\text { Avustralya, Avusturya, Belçika, Kanada, Güney Kıbrıs Rum Kesimi, Çek } \\
\text { Cumhuriyeti, Almanya, Danimarka, İspanya, Estonya, Finlandiya, } \\
\text { Fransa, Birleşik Krallık, Yunanistan, Hırvatistan, Macaristan, İrlanda, } \\
\text { İsrail, İtalya, Japonya, Güney Kore, Lüksemburg, Hollanda, Norveç, } \\
\text { Polonya, Portekiz, Singapur, Slovakya, Slovenya, İsveç, ABD }\end{array}$ \\
\hline
\end{tabular}

Sistem Genelleştirilmiş Momentler Metodu tahmincileri ise olumsuz koşullarda dahi tutarlı tahmincilere olanak sağlamaktadır. Blundell-Bond (1998) sistem-GMM tahmincilerinin sonlu örneklem durumunda dahi fark GMM'e göre daha sapmasız ve daha kesin tahminciler olduğunu Monte Carlo simülasyonlarını kullanarak göstermiştir. Sistem-GMM yöntemi ile yapılan tahminlerin geçerli olması için araç değişkenlerin dışsal olduğu varsayılmaktadır. Analiz sonuçlarında yer alan Sargan testi araç değişkenlerin tutarlı olup olmadığını test etmektedir.

Modelde otokorelasyonun varlığını Arrelano-Bond yöntemiyle test eden $A R(1)$ ve $A R(2)$ sonuçları yer almaktadır. Modele ait $A R(1)$ test sonucunun değerinin negatif olması beklenmektedir fakat modelin tutarlılığı açısından bu testin bir gerekliliği bulunmamaktadır. Model için $\mathrm{AR}(2)$ test istatistiği önemli olup sonucun istatistiksel olarak anlamsız bulunması gerekmektedir. 


\section{Model}

Ekonomik gelişmenin gelir eşitsizliği üzerindeki etkisini tespit etmek için Kuznets (1955)'in ters-U hipotezi sınanmıştır. Bu hipoteze ait temel model aşağıdaki gibi ifade edilebilir:

$$
G I N I_{i, t}=\beta_{0}+\alpha G I N I_{t-1}+\beta_{1} K B G S Y \dot{I} H_{i, t}+\beta_{2} K B G S Y \dot{I} H_{i, t}^{2}+\gamma X_{i, t}+\eta_{i}+\varepsilon_{i, t}
$$

Modeldeki bağımlı değişken GINI katsayısı gelir dağılımındaki eşitsizliği temsil ederken; $i$ ülkeleri, $t$ ise zaman boyutunu ifade etmektedir. Sağ tarafta açıklayıcı değişken olarak $K B G S Y I H$ ve $K B G S Y \dot{I} H^{2}$ sırasıyla kişi başı GSYiH ve kişi başı GSYiH'nın karesini ifade etmektedir. $X_{i, t}$ ise, dışa açıklık oranı (DIŞAÇıKLIK), enflasyon oranı (ENFLASYON), kişi başına GSYiH büyüme oranı (KBGSYiHBO), kamu harcamaları (KAMUHAR) ve eğitime katııım oranı (EĞiTiM) değişkenlerinden oluşan, kontrol değişken setini temsil eden vektördür. Kuznets (1955)'in ters-U hipotezini sınayabilmek için kişi başı GSYiH ve karesi modele açıklayıcı değişken olarak dahil edilmektedir. Kuznets hipotezi belirtildiği gibi büyümenin ekonomik gelişmenin başlangıç aşamalarında gelir eşitsizliğini artırdığıı; fakat ekonomik gelişmenin ileri aşamalarında gelir eşitsizliğini azalttığını iddia etmektedir. Dolayısıyla doğrusal olmayan bu ilişki için KBGSYIH değişkeninin katsayısının pozitif $\left(\beta_{1}>0\right) ; K B G S Y \dot{I} H^{2}$ değişkeninin katsayısının ise negatif $\left(\beta_{2}<0\right)$ olması beklenmektedir. Kullanılan tüm değişkenler, modele logaritmik olarak dahil edilmiştir. Bu nedenle katsayılar açıklayııı değişkenlerin gelir eşitsizliği üzerindeki esnekliklerini vermektedir.

\section{Tahmin ve Bulgular}

Kuznets hipotezini test edebilmek amacıyla ülkeler gelir sınıflandırmasına göre gruplandırılarak ayrı panellerde incelenmiştir. Tahmin sonuçları, düşük ve düşük-orta gelirli ülkeler, üst-orta gelirli ülkeler, yüksek gelirli ülkeler ve tüm ülkeler için verilmiştir. Kurulan modellerin tümünde otokorelasyonu test eden $A R(1), A R(2)$ ve kullanılan araç değişkenlerin tutarlılığını sınayan Sargan Test sonuçlarının uygun olduğu görülmektedir. 


\subsection{Düşük ve Düşük-Orta Gelirli Ülkelere Ait Bulgular}

Kuznets'in ekonomik gelişmenin başlangıç aşamalarında büyümenin gelir eşitsizliğini arttıracağı yönündeki hipotezi düşük ve düşük-orta gelirli ülkeler için sınanmaktadır. Kuznets hipotezine göre bu ülke grubunda ekonomik büyüme ile gelir eşitsizliğinin artması beklenmektedir. 1. modelin sonuçlarına bakıldığında bu hipotezin desteklendiği görülmektedir.

Tablo 2: Sistem-GMM Tahmin Sonuçları: Düşük ve Düşük-Orta Gelirli Ülkeler

\begin{tabular}{|c|c|c|}
\hline DEĞiŞKENLER & & \\
\hline $\begin{array}{l}\text { GiNi } \\
\text { (Bağımlı Değissken) }\end{array}$ & $\begin{array}{r}\text { Model } \\
(1)\end{array}$ & $\begin{array}{r}\text { Model } \\
\text { (2) }\end{array}$ \\
\hline LGINI & $\begin{array}{r}0.640^{* * *} \\
{[0.132]}\end{array}$ & $\begin{array}{r}0.694^{* * *} \\
{[0.118]}\end{array}$ \\
\hline DIŞAÇIKLIK & $\begin{array}{r}-0.017 \\
{[0.064]}\end{array}$ & $\begin{array}{r}0.023 \\
{[0.069]}\end{array}$ \\
\hline ENFLASYON & $\begin{array}{r}0.013 \\
{[0.018]}\end{array}$ & $\begin{array}{r}0.008 \\
{[0.018]}\end{array}$ \\
\hline KBGSYIHBO & $\begin{array}{r}-0.011^{* *} \\
{[0.005]}\end{array}$ & $\begin{array}{l}-0.011^{*} \\
{[0.006]}\end{array}$ \\
\hline KAMUHAR & $\begin{array}{r}0.001 \\
{[0.029]}\end{array}$ & $\begin{array}{r}-0.014 \\
{[0.032]}\end{array}$ \\
\hline ЕĞітім & $\begin{array}{r}-0.157^{* * *} \\
{[0.043]}\end{array}$ & $\begin{array}{r}-0.130 * * * \\
{[0.047]}\end{array}$ \\
\hline KBGSYiH & $\begin{array}{r}1.657 * * * \\
{[0.616]}\end{array}$ & $\begin{array}{r}0.053^{* *} \\
{[0.026]}\end{array}$ \\
\hline KBGSYIH^2 & $\begin{array}{r}-0.116 * * \\
{[0.045]}\end{array}$ & \\
\hline Sabit Terim & $\begin{array}{r}-3.993 * * \\
{[1.939]}\end{array}$ & $\begin{array}{r}1.089 * * \\
{[0.486]}\end{array}$ \\
\hline Ülke Sayısı & 23 & 23 \\
\hline AR(1) & $\begin{array}{r}-1.300 \\
{[0.193]}\end{array}$ & $\begin{array}{r}-1.286 \\
{[0.198]}\end{array}$ \\
\hline $\operatorname{AR}(2)$ & $\begin{array}{r}0.702 \\
{[0.482]}\end{array}$ & $\begin{array}{r}0.697 \\
{[0.485]} \\
\end{array}$ \\
\hline Sargan Test & $\begin{array}{l}67.797 \\
{[0.737]}\end{array}$ & $\begin{array}{l}69.087 \\
{[0.728]}\end{array}$ \\
\hline Wald-chi2 & 1294 & 3139 \\
\hline
\end{tabular}


Açıklayıcı değişken olan kişi başı GSYiH ve kişi başı GSYiH'nın karesi sırasıyla \%1 ve \%5 düzeyinde istatistiksel olarak anlamlıdır. Ayrıca bu değişkenlere ait katsayılar beklenildiği gibi sırasıyla pozitif $\left(\beta_{1}>0\right)$ ve negatif $\left(\beta_{2}<0\right)$ işaretlidir. Dolayısıyla bu örneklem çerçevesinde, ekonomik gelişme ve gelir eşitsizliği arasında ters-U şeklinde anlamlı bir ilişkinin var olduğu ifade edilebilir. 2. model ise yalnızca kişi başına GSYiH'nın etkisini kontrol etmektedir. Yine bu değişkene ait katsayı da pozitif işaretli ve \%5 seviyesinde istatistiksel olarak anlamlıdır.

Kuznets hipotezinin sınanmasının yanı sıra gelir eşitsizliğini etkilediği düşünülen diğer kontrol değişkenlerin etkisi de Tablo 2 de verilmiştir. Eğitime katılım oranı değişkeni iki modelde de \%1 düzeyinde istatistiksel olarak anlamlıdır ve negatif işarete sahiptir. Bu ise eğitime katılım oranı ya da eğitim seviyesi artıkça düşük gelirli ülkelerde gelir eşitsizliğinin azalacağı şeklinde yorumlanabilir. Dışa açıklık oranı, kamu harcamaları anlamsız iken, kişi başı GSYiH büyüme oranı değişkenlerine ait katsayılar ise anlamlı ve negatif işarete sahiptir, dolayısıyla kişi başı GSYiH büyüme oranı değişkenindeki artış bu panelde eşitsizliği azaltmaktadır. Kontrol değişkenlerden enflasyon oranına bakılırsa katsayısı anlamsız ve beklenildiği gibi pozitif işaretlidir.

\section{2. Üst-Orta Gelirli Ülkelere Ait Bulgular}

Kuznets hipotezine göre üst orta gelirli ülkelerde ekonomik büyüme ile gelir eşitsizliğindeki artış hızının yavaşlaması ve tersine dönme eğiliminin etkisine girmiş olması beklenmektedir. Hipotezi test eden modeller Tablo 3'de gösterilmektedir.

Analiz sonuçlarına göre Kuznets'in ters-U hipotezi bu panelde de doğrulanmaktadır. Hem kişi başı GSYiH hem de karesi \%10 düzeyinde istatistiksel olarak anlamlı ve sırasıyla pozitif ve negatif işarete sahiptir. Bu sonuçlar; üst-orta gelir seviyesine sahip ülkelerde ekonomik gelişmenin gelir eşitsizliğini, gelişmenin başlangıç aşamalarında arttırdığı ve ekonomik gelişmenin ileri aşamalarında ise gelir eşitsizliğini daralttığı şeklinde yorumlanabilir. 
Tablo 3: Sistem-GMM Tahmin Sonuçları: Üst-Orta Gelirli Ülkeler

\begin{tabular}{|c|c|c|}
\hline \multirow{3}{*}{$\begin{array}{l}\text { DEĞişKENLER } \\
\text { GiNi } \\
\text { (Bağımlı Değişken) }\end{array}$} & \multicolumn{2}{|c|}{$\begin{array}{c}\text { Kuznets } \\
\text { Ters-U Hipotezi }\end{array}$} \\
\hline & Model & Model \\
\hline & (1) & (2) \\
\hline \multirow[t]{2}{*}{ LGINI } & $0.387^{* * *}$ & $0.414 * * *$ \\
\hline & [0.063] & [0.065] \\
\hline \multirow[t]{2}{*}{ DIŞAÇIKLIK } & $-0.211 * * *$ & $-0.213 * * *$ \\
\hline & [0.053] & [0.052] \\
\hline \multirow[t]{2}{*}{ ENFLASYON } & 0.015 & 0.012 \\
\hline & {$[0.014]$} & [0.013] \\
\hline \multirow{2}{*}{ KBGSYінBO } & $0.014^{*}$ & $0.016 * *$ \\
\hline & {$[0.008]$} & [0.008] \\
\hline \multirow[t]{2}{*}{ KAMUHAR } & 0.041 & 0.033 \\
\hline & {$[0.116]$} & [0.106] \\
\hline \multirow[t]{2}{*}{ EĞітім } & 0.044 & 0.050 \\
\hline & {$[0.052]$} & [0.051] \\
\hline \multirow[t]{2}{*}{ KBGSYIH } & $1.415^{*}$ & 0.018 \\
\hline & {$[0.845]$} & [0.058] \\
\hline \multirow[t]{2}{*}{ KBGSYIH^2 } & $-0.085^{*}$ & \\
\hline & [0.051] & \\
\hline \multirow[t]{2}{*}{ Sabit Terim } & -2.997 & $2.604 * * *$ \\
\hline & [3.353] & [0.404] \\
\hline Ülke Sayısı & 28 & 28 \\
\hline \multirow{2}{*}{ AR(1) } & -2.788 & -2.866 \\
\hline & {$[0.005]$} & [0.004] \\
\hline \multirow[t]{2}{*}{$\operatorname{AR}(2)$} & 1.447 & 1.598 \\
\hline & {$[0.148]$} & [0.110] \\
\hline \multirow[t]{2}{*}{ Sargan Test } & 83.525 & 83.527 \\
\hline & {$[0.867]$} & [0.867] \\
\hline Wald-chi2 & 289.3 & 289.2 \\
\hline
\end{tabular}

Kullanılan kontrol değişkenlerine ait sonuçlar ise bu panelde düşük ve düşük-orta gelirli ülkelere ait panele göre anlamlıık düzeyi ve katsayıların işaretleri açısından oldukça farklılıklar sergilemektedir. İlk olarak eğitime katılım oranı değişkenine ait katsayılar, bu panelde anlamsız ve pozitif işarete sahiptir. Dışa açıklık oranı ise buradaki iki modelde de \%1 düzeyinde istatistiksel olarak anlamlıdır ve negatif işarete sahiptir. Dışa açıklık oranındaki artışların gelir eşitsizliğini azalttığı görülmektedir. Kişi başı GSYiH büyüme oranı ilk panelde olduğu gibi anlamlı fakat pozitif işarete sahiptir. Dolayısıyla kişi başı GSYiH büyüme oranındaki artışlar gelir eşitsizliğini arttırmaktadır. Son olarak hem enflasyon oranı hem de kamu harcamaları anlamsız ve pozitif işaretlidir. 


\subsection{Yüksek Gelirli Ülkelere Ait Bulgular}

Yüksek gelirli ülkeler grubunda Kuznets hipotezine göre ekonomik büyüme ile gelir eşitsizliğinin azalması beklenmektedir. Yapılan analiz sonuçlarında 2. modeldeki kişi başı GSYiH değişkeni katsayısı \%10 düzeyinde anlamlı ve negatif işaretlidir. Dolayısıyla ekonomik gelişme yüksek gelirli ülkelerde, hipotezi doğrular nitelikte, gelir eşitsizliğini azaltmaktadır.

Tablo 4: Sistem-GMM Tahmin Sonuçları: Yüksek Gelirli Ülkeler

\begin{tabular}{|c|c|c|}
\hline \multirow{2}{*}{$\begin{array}{l}\text { DEĞişKENLER } \\
\text { GiNi } \\
\text { (Bağımlı Değişken) }\end{array}$} & \multicolumn{2}{|c|}{$\begin{array}{c}\text { Kuznets } \\
\text { Ters-U Hipotezi }\end{array}$} \\
\hline & $\begin{array}{r}\text { Model } \\
\text { (1) }\end{array}$ & $\begin{array}{r}\text { Model } \\
\text { (2) }\end{array}$ \\
\hline LGINI & $\begin{array}{r}0.642 * * * \\
{[0.125]}\end{array}$ & $\begin{array}{r}0.648^{* * *} \\
{[0.132]}\end{array}$ \\
\hline DIŞAÇIKLIK & $\begin{array}{r}-0.090 \\
{[0.058]}\end{array}$ & $\begin{array}{r}-0.098 \\
{[0.065]}\end{array}$ \\
\hline ENFLASYON & $\begin{array}{r}-0.038 \\
{[0.026]}\end{array}$ & $\begin{array}{r}-0.036 \\
{[0.027]}\end{array}$ \\
\hline KBGSYIHBO & $\begin{array}{r}0.019^{* * *} \\
{[0.007]}\end{array}$ & $\begin{array}{r}0.019 * * * \\
{[0.007]}\end{array}$ \\
\hline KAMUHAR & $\begin{array}{r}0.232 \\
{[0.184]}\end{array}$ & $\begin{array}{r}0.237 \\
{[0.166]}\end{array}$ \\
\hline EĞітім & $\begin{array}{r}0.013 \\
{[0.061]}\end{array}$ & $\begin{array}{r}0.011 \\
{[0.061]}\end{array}$ \\
\hline KBGSYIH & $\begin{array}{r}-0.234 \\
{[1.451]}\end{array}$ & $\begin{array}{l}-0.042^{*} \\
{[0.024]}\end{array}$ \\
\hline KBGSYIH^2 & $\begin{array}{r}0.010 \\
{[0.074]}\end{array}$ & \\
\hline Sabit Terim & $\begin{array}{r}2.274 \\
{[6.768]} \\
\end{array}$ & $\begin{array}{l}1.343^{*} \\
{[0.796]}\end{array}$ \\
\hline Ülke Sayısı & 28 & 28 \\
\hline AR(1) & $\begin{array}{r}-2.628 \\
{[0.008]}\end{array}$ & $\begin{array}{r}-2.517 \\
{[0.011]}\end{array}$ \\
\hline$A R(2)$ & $\begin{array}{r}-1.169 \\
{[0.242]}\end{array}$ & $\begin{array}{r}-1.134 \\
{[0.257]}\end{array}$ \\
\hline Sargan Test & $\begin{array}{l}37.491 \\
{[0.086]}\end{array}$ & $\begin{array}{l}36.601 \\
{[0.102]}\end{array}$ \\
\hline Wald-chi2 & 210.3 & 107.8 \\
\hline
\end{tabular}


Kuznets'in ters-U hipotezinin test edildiği 1. modelde kişi başı GSYiH ve karesinin katsayıları anlamsız ve işaretleri hipotezin tersi yöndedir. Bu sonuçlarda katsayı işaretlerinin diğer iki panelden farklı olması aslında Kuznets eğrisinin doğrulandığı şeklinde yorumlanabilir. Çünkü ekonomik gelişmenin, düşük ve düşük-orta gelirli ülkeler ve üst-orta gelirli ülkelerde gelir eşitsizliğini arttıran, yüksek gelirli ülkelerde ise gelir eşitsizliğini azaltan etki yaratması Kuznets hipotezine dolaylı olarak kanıtlar sunmaktadır.

Çalışmada kullanılan kontrol değişkenlerinden dışa açıklık oranının bu panelde negatif işaretli olduğu ve eşitsizlik üzerinde etkisi olmadığı görülmektedir. Enflasyon oranına ait katsayılar düşük ve düşük-orta gelirli ülkeler ve üst-orta gelirli ülkelerden farklı olarak negatiftir. Her iki modelde de \%1 düzeyinde anlamlı ve beklenenin aksine pozitif işaretli olan kontrol değişkeni kişi başı GSYiH büyüme oranı iken; eğitime katılım oranı değişkeninin katsayıları modellerde anlamsız olmasına rağmen pozitif işaretlidir. Son olarak kamu harcamalarına ait sonuçlar da pozitif katsayıya sahip ve anlamsızdır.

\subsection{Tüm Ülkelere Ait Bulgular}

Son panelde tüm ülke grup verileri bir arada değerlendirilmiştir. Tüm ülkelere göre yapılan analizin bulguları da Kuznets'in ters-U hipotezini destekleyen sonuçlar göstermiştir. Kuznets hipotezinin test edildiği 1. modelde beklenildiği gibi kişi başı GSYiH değişkeninin katsayısı pozitif işaretli ve $\% 5$ düzeyinde anlamlı ve bu değişkenin karesine ait katsayı negatif işaretli ve \%5 düzeyinde anlamlı iken kişi başı GSYiH değişkeninin katsayısı 2 . modelde anlamsız ve pozitif işaretlidir.

Kontrol değişkenler incelendiğinde eğitime katılım oranı değişkeni negatif işaretli ve ikinci modelde \%10 düzeyinde istatistiksel olarak anlamlı olduğu görülmektedir. Yani ülkedeki eğitim seviyesinde yaşanan artışın gelir eşitsizliğini azaltma da önemli bir rol oynadığı söylenebilir. Panelde dışa açıklık oranı negatif işaretli fakat anlamsızdır. Kişi başı GSYiH büyüme oranı pozitif katsayıya sahip ve 1 . Modelde \%10 düzeyinde istatistiksel olarak anlamlıdır. Kontrol değişkenlerden son olarak enflasyon oranı ve kamu harcamaları değişkenlerinin katsayıları pozitif ve anlamsızdır. 
Tablo 5: Sistem-GMM Tahmin Sonuçları: Tüm Ülkeler

\begin{tabular}{|c|c|c|}
\hline DEĞiŞKENLER & Ter & \\
\hline $\begin{array}{l}\text { GiNi } \\
\text { (Bağımlı Değişken) }\end{array}$ & $\begin{array}{r}\text { Model } \\
\text { (1) }\end{array}$ & $\begin{array}{r}\text { Model } \\
\text { (2) }\end{array}$ \\
\hline LGINI & $\begin{array}{r}0.437 * * * \\
{[0.124]}\end{array}$ & $\begin{array}{r}0.556 * * * \\
{[0.093]}\end{array}$ \\
\hline DIŞAÇIKLIK & $\begin{array}{r}-0.116 \\
{[0.072]}\end{array}$ & $\begin{array}{r}-0.090 \\
{[0.055]}\end{array}$ \\
\hline ENFLASYON & $\begin{array}{r}0.004 \\
{[0.009]}\end{array}$ & $\begin{array}{r}0.008 \\
{[0.008]}\end{array}$ \\
\hline KBGSYIHBO & $\begin{array}{l}0.009^{*} \\
{[0.006]}\end{array}$ & $\begin{array}{l}0.010^{*} \\
{[0.006]}\end{array}$ \\
\hline KAMUHAR & $\begin{array}{r}0.005 \\
{[0.072]}\end{array}$ & $\begin{array}{r}0.070 \\
{[0.054]}\end{array}$ \\
\hline ЕĞітім & $\begin{array}{r}-0.067 \\
{[0.047]}\end{array}$ & $\begin{array}{l}-0.066^{*} \\
{[0.036]}\end{array}$ \\
\hline KBGSYiH & $\begin{array}{r}0.741 * * \\
{[0.327]}\end{array}$ & $\begin{array}{r}0.023 \\
{[0.021]}\end{array}$ \\
\hline KBGSYIH^2 & $\begin{array}{r}-0.042^{* *} \\
{[0.019]}\end{array}$ & \\
\hline Sabit Terim & $\begin{array}{r}-1.520 \\
{[1.408]}\end{array}$ & $\begin{array}{r}0.682 \\
{[0.538]} \\
\end{array}$ \\
\hline Ülke Sayısı & 62 & 62 \\
\hline$A R(1)$ & $\begin{array}{r}-2.957 \\
{[0.003]}\end{array}$ & $\begin{array}{r}-3.065 \\
{[0.002]}\end{array}$ \\
\hline$A R(2)$ & $\begin{array}{r}0.236 \\
{[0.813]}\end{array}$ & $\begin{array}{r}0.462 \\
{[0.644]}\end{array}$ \\
\hline Sargan Test & $\begin{array}{r}126.387 \\
{[0.150]}\end{array}$ & $\begin{array}{l}60.956 \\
{[0.184]}\end{array}$ \\
\hline Wald-chi2 & 131.3 & 216.1 \\
\hline
\end{tabular}

Not: Sağlam (Robust) standart hatalar kullanılmış ve parantez içerisinde verilmiştir. ${ }^{* * *} p<0.01,{ }^{* *} p<0.05,{ }^{*} p<0.1$ anlam düzeylerini temsil etmektedir. $A R(1), A R(2)$ ve Sargan Test istatistiklerine ait "prob" değerleri parantez içerisinde yer almaktadır.

\section{Sonuç}

Çalışmada gelir eşitsizliği ve ekonomik büyüme arasındaki ilişki; 1995-2011 dönemi için 94 ülkenin veri seti ile Kuznets (1955)'in ters-U hipotezi kullanılarak sınanmıştır. 94 ülke gelir seviyesine göre gruplandırılarak iki değişken arasındaki ilişki ayrı ayrı panellerde incelenmiştir. Son panelde tüm ülkelerin verisi ile hipotez sınaması yapılmıştır. Ülke sınıflandırılmasındaki temel amaç ülkelerin gelişmişlik düzeylerine göre eşitsizliğin hangi yönde hareket ettiğini tespit etmektir. 
Ekonomik gelişme ve gelir eşitsizliği ilişkisinin incelendiği modellere bakıldığında elde edilen bulguların Kuznets (1955)'in ters-U hipotezini destekleyen kanıtlar sunduğu görülmektedir. Değişkenlere ait katsayıların çoğu beklenen işaretlere sahip, istatistiksel olarak anlamlıdır. Ekonomik gelişme düşük ve düşük-orta gelirli, üst orta gelirli ve tüm ülkelerin kullanıldığı panellerde gelir eşitsizliğini artırıcı yüksek gelirli ülkelerde ise azaltıcı bir rol oynamaktadır. Eşitsizliğin, ekonomik gelişme karşııında düşük ve düşük-orta gelirli ile üst orta gelirli ülkelerde artarken; yüksek gelirli ülkelerde azalması ters-U şeklinde bir ilişkinin varlığını doğrulamaktadır. Bu nedenle gelir eşitsizliği, ülkelerde sürekli bir ekonomik gelişme süreci karşısında ters-U şeklinde bir hareketi takip etmektedir.

Analizde elde edilen sonuçlar değerlendirildiğinde; toplumun başlangıçtaki gelir seviyesi, ekonomik gelişme karşısında eşitsizliğin yönünün nasıl olacağını belirlemektedir. Bu nedenle politika yapıcılar ekonomik gelişme gelir eşitsizliği kavramlarını birbirinden ayırmamalı; sadece ekonomik büyümeye değil gelir dağılımı politikalarına da önem vermelidir. Bunların yanı sıra gelir eşitsizliğini etkilediği düşünülen ve analizde de kontrol değişkeni olarak kullanılan değişkenler gelir eşitsizliğini iyileştirici politika kararları alınırken göz önünde bulundurulabilir.

\section{Kaynaklar}

Ahluwalia, M.S. (1976), "Inequality, poverty and development", Journal of Development Economics, Vol. 3, 307-42.

Arellano, M., ve Bover, O. (1995), "Another Look At The Instrumental Variables Estimation Of Errorcomponents Models", Journal of Econometrics, C. 68, 29-51.

Arrelano, M. ve Bond, S. (1991), "Some Tests of Specification for Panel Data: Monte Carlo Evidence and an Application to Employment Equations.", Review of Economic Studies, C. 58, No: 2.

Alesina, A., ve Rodrik D., (1994), "Distributive Politics and Economic Growth," Quarterly Journal of Economics, 465-490.

Banerjee, A. V., ve Duflo, E. (2003), "Inequality and growth: What can the data say?", Journal of economic growth, 8(3), 267-299.

Barro, R. (2000), "Inequality and Growth in a Panel of Countries", Journal of Economic Growth C. 5, No: 1, 5-32.

Barro, R. J. (2008), "Inequality and growth revisited", ADB Working paper series on regional economic integration, (No. 11).

Bengoa-Calvo, M., ve Sánchez-Robles, B. (2004), "Economic growth and inequality in Latin-American Countries: Some empirical findings", Available at SSRN 525882. 
Blundell, R., ve Bond, S. (1998), "Initial Conditions And Moment Restrictions in Dynamic Panel Data Models", Journal of Econometrics, C. 87, 115-143.

Brussolo, M. E. (2011), "The kuznets hypothesis revisited: Exploring mexican inequality at the sub-national level" (Order No. 3455596), Available from ProQuest Dissertations \& Theses Global. (868713427). http://search.proquest.com/docview/868713427?accountid=16716, (Erişim Tarihi: 01.11.2015).

Castelló, A., ve Doménech, R. (2002), "Human capital inequality and economic growth: some new evidence", The economic journal, 112(478), C187-C200.

Chen, B-L. (2003), "An inverted-U relationship between inequality and longrun growth", Economic Letters, 78(2), 205-212.

Dawson, P. (1997), “On testing Kuznets' economic growth hypothesis”, Applied Economic Letter, Vol. 4 No. 7, 409-10.

Dağdemir, Ö. (2008), “Küreselleşmenin gelişmekte olan ülkelerde gelir dağılımı üzerindeki etkileri”, iktisat Isletme ve Finans, 23(265), 114-129.

Deininger, K. ve Squire, L. (1996), "A new data set measuring income inequality", World Bank Economic Review, Vol. 10, 565-91.

Forbes, Kristin J. (2000), "A reassessment of the relationship between inequality and growth." American economic review, 869-887.

Huang, H. C. R. (2004), "A flexible nonlinear inference to the Kuznets hypothesis", Economics Letters, 84(2), 289-296.

Khasru, S. M., ve Jalil, M. M. (2004), "Revisiting Kuznets hypothesis: An analysis with time series and panel data", The Bangladesh Development Studies, 89-112.

Kuznets, S. (1955), "Economic Growth and Income Inequality". The American Economic Review C. 45(1).

Kuznets, S. (1963), "Quantitative aspects of economic growth of nations: III, distribution of income by size", Economic Development and Cultural Change, Vol. 11, $1-80$.

Lee, W., ve Roemer, J. E. (1998), "Income distribution, redistributive politics, and economic growth". Journal of Economic Growth, 3(3), 217-240.

Li, H., ve Zou H. (1998), "Income inequality is not harmful for growth: theory and evidence." Review of development economics 2.3, 318-334.

Malinen T. (2012), "Estimating the long-run relationship between income inequality and economic development". Empirical Economics, forthcoming. 
Ongan, T. H. (2004), “Gelir Eşitsizliği, Doğrudan Yabancı Sermaye Yatırımları ve Ters U Eğrisi”, İktisat Fakültesi Mecmuası, 54(1), 153.

Partridge, Mark D. (1997), "Is inequality harmful for growth? Comment." The American Economic Review 87.5, 1019-1032.

Paukert, F. (1973), "Income Distribution at Different Levels of Development: A Survey of Evidence", International Labour Review 108, 97-125.

Persson, T. ve Tabellini, G., (1994), "Is inequality harmful for growth: Theory and evidence", American Economic Review, 84(3), 600-621.

Piketty, T. (2014), Yirmi Birinci Yüzyılda Kapital (Çeviren: Hande Koçak): Türkiye iş̧ Bankası Kültür Yayınları, inceleme/Araştırma, 1.

Ram, R. (1989), "Level of Development and Income Inequality: An Extension of Kuznets-Hypothesis to the World Economy", Kyklos, 42(1), 73-88.

Ram, R. (1997), "Level of economic development and income inequality: evidence from the postwar developed world", Southern Economic Journal, Vol. 64, 576-83.

Shahbaz, M. (2010), "Income inequality-economic growth and non-linearity: a case of Pakistan", International Journal of Social Economics, 37(8), 613-636.

Shin, I., (2012), "Income inequality and economic growth". Economic Modelling, 29(5), 2049-2057.

Thornton, J. (2001), "The Kuznets inverted-U hypothesis: panel data evidence from 96 countries", Applied Economics Letters, 8(1), 15-16.

Tokatlıoğlu, I., ve Atan, M. (2007), "Türkiye'de Bölgeler Arası Gelişmişlik Düzeyi Ve Gelir Dağılımı Eşitsizliği: Kuznets Eğrisi Geçerli Mi?”, Ekonomik Yaklaşım, 18(65), 2558. 